\title{
Hearing difficulty and its psychological implications for the elderly
}

\author{
DEE A JONES, CHRISTINA R VICTOR, AND NORMAN J VETTER \\ From the Research Team for the Care of the Elderly, Welsh National School of Medicine, St David's Hospital, \\ Cardiff, $U K$
}

SUMMARY A random sample of patients aged 70 and over from a general practice were interviewed in their own homes. Information was sought on their hearing difficulty and mental state: standardised measures of anxiety, depression, and memory loss were used. Of the 657 subjects interviewed, $33 \%$ reported having difficulty hearing normal conversations and $6 \%$ reported experiencing "much difficulty." Hearing difficulty was associated with both depression and anxiety, but the associations weakened when adjustment was made for physical disability. The association with memory loss disappeared when adjusted for physical disability. There was a close relationship both with age and physical disability.

For many years hearing loss has been reported as one of the many disabilities associated with increasing age. ${ }^{1}$ Studies of the prevalence of hearing loss in the elderly in the community show that $30-40 \%$ of all people of retirement age report some degree of hearing difficulty.$^{12}$ More recently, using audiometric techniques, Herbst has reported a prevalence of $60 \% .^{3}$

It is generally accepted that deafness inevitably leads to a breakdown in communication and consequent physical and mental problems, and therefore a higher degree of social isolation. Nevertheless, few community based studies have been undertaken to examine both the mental and more general physical state of the elderly with hearing difficulty. This study therefore sought to examine the elderly living in the community in a general practice who reported experiencing difficulty with hearing, and also to investigate the relationships between this and their mental and physical disability.

\section{Method}

This study was based on a large urban six handed general practice in the centre of a medium sized town in South Wales. A random sample (40\%) of the over 70 s, extracted from the age-sex register, provided the names and addresses of 683 subjects. A team of five trained fieldworkers then interviewed 657 in their own homes (response rate 96\%). The standardised interview schedule included questions on such topics as physical and mental disabilities, social life, and housing.

Concerning hearing difficulty, each subject was asked "Do you have any difficulty hearing ordinary conversation (even when wearing your hearing aid)?" The answers were coded as "No," "a little difficulty," or "a lot of difficulty." The interviewers made their own assessment of the subject's hearing difficulty using the same categories.

The measurement of physical disability was based on the concept of disability and dependency-as difficulty with, or the inability to perform, certain basic functions essential to the maintenance of independent living. This provided an overall measure of functional physical disability ${ }^{4}$ and included questions on the ability of the old person to manage nine basic functions when alone. These ranged from activities such as carrying heavy shopping or catching buses to climbing stairs and cooking a meal. The overall score has a range of $0-18$; Townsend regards people with a score of zero as having no disability, 1 or 2 slightly affected, 3-6 some, 7-10 appreciable, 11-18 severe and very severe. Three measures of mental disability-anxiety, depression, and memory-were included in the interview schedule. The items included in the anxiety and depression questionnaires were chosen from a larger set of questions ${ }^{5}$ and have been tested on the elderly at home and validated by comparing the scores with psychiatric opinions. ${ }^{6}$ They have been used and 
validated in old people in general practice. ${ }^{7}$

The questionnaires consist of a series of questions about symptoms of anxiety and depression within the past month. For each question a score of $0-3$ is possible. The scores were added for each of seven questions, giving a range of $0-21$ for each scale. By comparison with a psychiatric opinion a score of $0-2$ was designated normal, 3-5 borderline, and 6-12 pathological.?

The measure of memory was a standard questionnaire ${ }^{8}$ the results of which have been shown at necropsy to be associated with brain damage relating to Alzheimer's disease. ${ }^{9}$

\section{Results}

Thirty three per cent of subjects reported having difficulty hearing normal conversation and $6 \%$ had "much difficulty" (table 1). The interviewers assessed $35 \%$ as having difficulty and $7 \%$ as "much difficulty."

When the fieldworkers' and the subjects' assessments were compared $82 \%$ were categorised similarly; only four people were classified as "no difficulty" and "much difficulty," and $17 \%$ as "no difficulty" and "some difficulty;" none was classified as "no difficulty" and "much difficulty."

Table 1 Hearing difficulty by sex

\begin{tabular}{lccccccc}
\hline & \multicolumn{1}{c}{ Men } & \multicolumn{2}{c}{ Women } & \multicolumn{2}{c}{ Both sexes } \\
\cline { 2 - 8 } Hearing & No & $\%$ & No & $\%$ & No & $\%$ \\
\hline No difficulty & 162 & 65 & 279 & 69 & 441 & 67 \\
Some difficulty & 81 & 32 & 98 & 24 & 179 & 27 \\
Much difficulty & 7 & 3 & 30 & 7 & 37 & 6 \\
\hline Total & 250 & 100 & 407 & 100 & 657 & 100 \\
\hline
\end{tabular}

There was a very close association between age and hearing difficulty $\left(\chi^{2}=48 \cdot 5, \mathrm{p}<0.0005\right), 22 \%$ of the over 85 s reported having "much difficulty" (table 2 ).

Table 2 Hearing difficulty by age (years)

\begin{tabular}{|c|c|c|c|c|c|c|c|c|}
\hline \multirow[b]{2}{*}{ Hearing } & \multicolumn{2}{|c|}{$70-74$} & \multicolumn{2}{|c|}{$75-79$} & \multicolumn{2}{|c|}{$80-84$} & \multicolumn{2}{|l|}{$>85$} \\
\hline & No & $\%$ & No & $\%$ & No & $\%$ & No & $\%$ \\
\hline No difficulty & 195 & 76 & 152 & 68 & 68 & 59 & 26 & 44 \\
\hline Some difficulty & 57 & 22 & 62 & 28 & 40 & 35 & 20 & 34 \\
\hline Much difficulty & 6 & 2 & 10 & 5 & 8 & 7 & 13 & 22 \\
\hline Total & 258 & 100 & 224 & 101 & 116 & 101 & 59 & 100 \\
\hline
\end{tabular}

Those with hearing difficulty had an increasing likelihood of being scored as borderline or neurotic on the anxiety questionnaire (table 3$)\left(\chi^{2}=21 \cdot 1\right.$, $\mathrm{df}=4, \mathrm{p}<0.0005) ; 55 \%$ of those with much difficulty scored as borderline or neurotic on the anxiety questionnaire.

Table 3 Anxiety score by hearing difficulty

\begin{tabular}{|c|c|c|c|c|c|c|}
\hline \multirow[b]{2}{*}{ Anxiety } & \multicolumn{2}{|c|}{ No difficulty } & \multicolumn{2}{|c|}{ Some difficulty } & \multicolumn{2}{|c|}{ Much difficulty } \\
\hline & No & $\%$ & No & $\%$ & No & $\%$ \\
\hline Normal & 308 & 72 & 106 & 62 & 14 & 45 \\
\hline Borderline & 86 & 20 & 42 & 25 & 8 & 26 \\
\hline Neurotic & 32 & 8 & 22 & 13 & 9 & 29 \\
\hline Total & 426 & 100 & 170 & 100 & 31 & 100 \\
\hline
\end{tabular}

There was also an increased prevalence of depression among those that had difficulty in hearing (table 4): $30 \%$ of those with much difficulty scored as abnormal. Once again the association was significant $\left(\chi^{2}=17 \cdot 1, \mathrm{df}=4, \mathrm{p}<0.005\right)$.

Table 4 Depression score by hearing difficulty

\begin{tabular}{|c|c|c|c|c|c|c|}
\hline \multirow[b]{2}{*}{ Depression } & \multicolumn{2}{|c|}{ No difficulty } & \multicolumn{2}{|c|}{ Some difficulty } & \multicolumn{2}{|c|}{ Much difficulty } \\
\hline & No & $\%$ & No & $\%$ & No & $\%$ \\
\hline Normal & 383 & 90 & 137 & 81 & 21 & 70 \\
\hline Borderline & 24 & 6 & 21 & 12 & 6 & 20 \\
\hline Neurotic & 19 & 4 & 12 & 7 & 3 & 10 \\
\hline Total & 426 & 100 & 170 & 100 & 30 & 100 \\
\hline
\end{tabular}

Hearing difficulty was not significantly associated with memory loss (table 5$)\left(x^{2} 1 \cdot 3, d f=4\right.$, $\mathrm{p}<0.90$ ).

The relationship between disability and hearing impairment was examined and there was a consistently strong association $\left(\chi^{2}=51 \cdot 18, \mathrm{df}=6\right.$, $\mathrm{p}<0.0005$ ) (table 6). There was also a significant relationship between dependency and hearing difficulty $\left(\chi^{2}=37 \cdot 79\right.$, df $\left.=2, \mathrm{p}<0.0005\right)$.

As physical disability was closely associated with hearing difficulty it was considered necessary to examine further the inter-relationships between disability, hearing difficulty, and mental disability. Each of the relationships between hearing difficulty and mental disability was examined, adjusting for physical disability. There was still a consistent but not significant association between hearing difficulty and anxiety $\left(\chi^{2}=7 \cdot 09, \mathrm{df}=4, \mathrm{p}<0 \cdot 2\right)$. There remained 
Table 5 Memory score by hearing difficulty

\begin{tabular}{|c|c|c|c|c|c|c|}
\hline \multirow[b]{2}{*}{ Memory } & \multicolumn{2}{|c|}{ No difficulty } & \multicolumn{2}{|c|}{ Some difficulty } & \multicolumn{2}{|c|}{ Much difficulty } \\
\hline & No & $\%$ & No & $\%$ & No & $\%$ \\
\hline Normal & 404 & 95 & 160 & 94 & 29 & 91 \\
\hline Mild & 18 & 4 & 8 & 5 & 2 & 6 \\
\hline Severe & 5 & 1 & 3 & 2 & 1 & 3 \\
\hline Total & 427 & 100 & 171 & 101 & 32 & 100 \\
\hline
\end{tabular}

Table 6 Physical disability by hearing difficulty

\begin{tabular}{|c|c|c|c|c|c|c|}
\hline \multirow{2}{*}{$\begin{array}{l}\text { Physical } \\
\text { disability }\end{array}$} & \multicolumn{2}{|c|}{ No difficulty } & \multicolumn{2}{|c|}{ Some difficulty } & \multicolumn{2}{|c|}{ Much difficulty } \\
\hline & No & $\%$ & No & $\%$ & No & $\%$ \\
\hline None & 207 & 47 & 59 & 33 & 3 & 8 \\
\hline Mild & 151 & 34 & 73 & 41 & 12 & 32 \\
\hline Moderate & 45 & 10 & 15 & 8 & 9 & 24 \\
\hline Severe & 36 & 8 & 31 & 17 & 13 & 35 \\
\hline Total & 439 & 99 & 178 & 99 & 37 & 99 \\
\hline
\end{tabular}

a consistent association with depression, but again the adjusted chi-square was not significant $\left(\chi^{2}=6 \cdot 86, \mathrm{df}=4, \mathrm{p}<0 \cdot 2\right)$. The relationship with memory loss disappeared almost completely when adjusted for disability and is reflected in the chi-square $(\chi=1 \cdot 19, \mathrm{df}=4, \mathrm{p}<0 \cdot 9)$.

\section{Discussion}

The finding that $33 \%$ of the sample reported experiencing difficulty hearing normal conversation is consistent with other studies using similar methods $^{12}$; Abrams reporting 36\% among a population aged 75 and over.

The prevalence of hearing difficulty was found to be closely associated with age as has been reported previously. ${ }^{23}$ Not surprisingly, there was a positive association between hearing difficulty and disability. Consequently, in the investigation of the relationships between hearing loss, anxiety, and mental disability, physical disability needs to be controlled for.

Anxiety had an association with hearing difficulty, but the strength weakened with adjustment for disability. Anxious people are perhaps more likely to be aware of or to report hearing difficulties; alternatively, hearing difficulty and consequent difficulties with social interaction may in fact cause anxiety among the elderly.
Depression was more prevalent among the hard of hearing, but when disability was controlled for the relationship weakened. This differs from the findings of previous workers, who concluded that there was a significant relationship between hearing difficulty and depression. ${ }^{3}$ Herbst adjusted for age but not for physical disability. From the present study disability seems to be the intermediate variable relating hearing loss to depression and anxiety.

Memory loss was associated with hearing difficulty, but the association disappeared when adjusted for disability: this result agrees with recent work $^{3}$ but not with the earlier study of Kay et al who considered the relationship to be independent of age and disability. ${ }^{10}$

Hearing difficulty among the over 70 s is often an added problem to the physically disabled. It appears to be related to anxiety and depression. To discuss further the effects of such hearing difficulties on the psychological life of the elderly, and whether the relationships are causal, the issue needs to be studied using a longitudinal approach, rather than cross sectional. It can at least be said that hearing difficulty further reduces the quality of life of those elderly already suffering physical disabilities. Only $18 \%$ of subjects possessed a hearing aid. As hearing impairment is more readily ameliorated than physical disability, the treatment of such widespread impairment demands more attention.

We would like to express sincere thanks to the Department of Health and Social Security; Dr H N Williams and partners, St David's Clinic, Clytha Square, Newport, Gwent; Mrs P Allen, Mrs D Bignell, Mrs D Ford, and Miss .S Tamplin (fieldworkers); and Mrs S R Whale (Secretary).

\section{References}

${ }^{1}$ Sheldon JH. The social medicine of old age. Report of an inquiry in Wolverhampton. London: Oxford University Press, 1948.

${ }^{2}$ Abrams M. Beyond three score years and ten. A first report on a survey of the elderly. Mitcham: Age Concern, 1978. (Research publication.)

${ }^{3}$ Herbst $\mathbf{K}$. Hearing impairment and mental state in the elderly living at home. $\mathrm{Br}$ Med J 1981; 281: 903-5.

'Townsend P. Poverty in the United Kingdom. Harmondsworth: Penguin Books, 1978.

${ }^{5}$ Foulds GA, Bedford A. Manual of the delusions-symptoms states inventory. Windsor: National Foundation for Educational Research Publishing Co, 1979.

${ }^{6}$ Bedford A, Foulds GA, Sheffield BF. A new personal disturbance scale DSSI/SAD. British Journal of Social and Clinical Psychology 1976; 15: 387-93. 
${ }^{7}$ McNab A, Philip AE. Screening an elderly population for psychological well-being. Health Bulletin 1980; 160.

${ }^{8}$ Wilson LA, Brass W. Brief assessment of the mental state in geriatric domiciliary practice. The usefulness of the mental status questionnaire. Age and Ageing 1973; 2: 92-101.
${ }^{\circ}$ Blessed G, Tomlinson BE, Roth M. The association between quantitive measures of dementia and senile change in cerebral grey matter of elderly subjects. $\mathrm{Br} \mathrm{J}$ Psychiatry 1968; 114: 797-802.

${ }^{10}$ Kay DWK, Beamish P, Roth M. Old age mental disorders in Newcastle-upon-tyne. Part I. B J Psychiatry 1964; 110: $146-58$. 